\title{
Increased global placental DNA methylation levels are associated with gestational diabetes
}

\author{
C. Reichetzeder ${ }^{2,4 \dagger}$, S. E. Dwi Putra ${ }^{1,5 \dagger}$, T. Pfab ${ }^{4,6}$, T. Slowinski $^{3}$, C. Neuber ${ }^{2}$, B. Kleuser $^{2 \dagger}$ and B. Hocher ${ }^{1,7,8^{*}+}$
}

\begin{abstract}
Background: Gestational diabetes mellitus (GDM) is associated with adverse pregnancy outcomes. It is known that GDM is associated with an altered placental function and changes in placental gene regulation. More recent studies demonstrated an involvement of epigenetic mechanisms. So far, the focus regarding placental epigenetic changes in GDM was set on gene-specific DNA methylation analyses. Studies that robustly investigated placental global DNA methylation are lacking. However, several studies showed that tissue-specific alterations in global DNA methylation are independently associated with type 2 diabetes. Thus, the aim of this study was to characterize global placental DNA methylation by robustly measuring placental DNA 5-methylcytosine $(5 \mathrm{mC})$ content and to examine whether differences in placental global DNA methylation are associated with GDM.

Methods: Global DNA methylation was quantified by the current gold standard method, LC-MS/MS. In total, 1030 placental samples were analyzed in this single-center birth cohort study.

Results: Mothers with GDM displayed a significantly increased global placental DNA methylation (3.22 \pm 0.63 vs. $3.00 \pm 0.46 \% ; p=0.013 ; \pm S D$ ). Bivariate logistic regression showed a highly significant positive correlation between global placental DNA methylation and the presence of GDM $(p=0.0009)$. Quintile stratification according to placental DNA $5 \mathrm{mC}$ levels revealed that the frequency of GDM was evenly distributed in quintiles 1-4 (2.9-5.3\%), whereas the frequency in the fifth quintile was significantly higher (10.7\%; $p=0.003)$. Bivariate logistic models adjusted for maternal age, BMI, ethnicity, recurrent miscarriages, and familiar diabetes predisposition clearly demonstrated an independent association between global placental DNA hypermethylation and GDM. Furthermore, an ANCOVA model considering known predictors of DNA methylation substantiated an independent association between GDM and placental DNA methylation.
\end{abstract}

Conclusions: This is the first study that employed a robust quantitative assessment of placental global DNA methylation in over a thousand placental samples. The study provides large scale evidence that placental global DNA hypermethylation is associated with GDM, independent of established risk factors.

Keywords: Placenta, Gestational diabetes, Insulin resistance, LC-MS/MS, Global DNA methylation, Epigenetics, Hypermethylation

\footnotetext{
* Correspondence:

hocher@uni-potsdam.de; http://www.uni-potsdam.de/eem

C. Reichetzeder and S. E. Dwi Putra are equally contributing first authors.

B. Kleuser and B. Hocher are equally contributing last authors.

†Equal contributors

${ }^{1}$ Department of Experimental Nutritional Medicine, Institute of Nutritional

Science, University of Potsdam, Arthur-Scheunert-Allee 114-116, Nuthetal,

Potsdam 14558, Germany

${ }^{7}$ Institut für Laboratoriumsmedizin, Berlin, Germany

Full list of author information is available at the end of the article
} 


\section{Background}

Gestational diabetes mellitus (GDM) is defined as any degree of glucose intolerance with a first recognition during pregnancy [1]. In population based studies, the prevalence of GDM varies from 1 to $14 \%$ with higher occurrences in specific populations [1, 2]. Ethnic disparities are existing, with Asians having the highest rate of GDM, followed by Hispanics, African Americans, and Caucasians [1]. GDM is associated with a markedly increased risk of adverse pregnancy outcome for both mother and infant. Mothers suffering from GDM have a higher risk for preeclampsia and cesarean delivery [3-5]. GDM pregnancies are associated with an increased perinatal morbidity and mortality, with an elevated risk for malformations, substantially higher rates of premature birth and neonatal hypoglycemia [3-5]. Newborns of pregnancies complicated by GDM show an increased risk to display altered growth patterns with increased neonatal body fat and a higher birth weight and ponderal index [3-5]. Evidence is accumulating that the intrauterine exposure to GDM also might contribute to long-lasting effects on the offspring by metabolic programming, leading to a higher disease susceptibility later in life [1]. Risk factors for GDM include age, a prepregnancy body mass index $(\mathrm{BMI})>25.0 \mathrm{~kg} / \mathrm{m}^{2}$, ethnic background, a history of GDM in previous pregnancies, glucosuria, a strong first-degree family history of type 2 diabetes or GDM, and a history of unexplained stillbirth or recurrent miscarriages $[6,7]$. The placenta is the primary means of communication between mother and fetus and a target for maternal and/or fetal metabolic disturbances associated with GDM. Placentas of diabetic pregnancies show an increased placental to fetal ratio and are characterized by pathohistological findings [8]. The increased risk for adverse pregnancy outcome in GDM may be associated with these placental structural and functional changes. The molecular pathways behind this are incompletely understood so far. It is known that GDM is associated with altered placental gene regulation, and there is data indicating an involvement of epigenetic mechanisms [9-13]. So far, the focus regarding placental epigenetic changes in GDM was predominantly set on gene specific DNA methylation [10-13]. There are several studies that applied genome wide approaches, using the Illumina Infinium 450K BeadChips assay that measures $\mathrm{CpG}$ island methylation in about $99 \%$ of all RefSeq genes [11-13]. However, such arrays only cover about $1.5 \%$ of overall genomic CpGs, are biased towards the measurement of promoter methylation, and neglect other regions and functions of DNA methylation, thus cannot be regarded as a method to measure global DNA methylation [14, 15]. Furthermore, only about $1.5 \%$ of the total genome sequence is comprised of protein encoding genes, while the remaining majority encompasses introns, repetitive elements, and other non-coding sequences [16]. Recent research has demonstrated important functions of DNA methylation in such non-coding genomic regions [14, 15, 17-19]. Although various sequencing methods are available for a detailed, site-specific analysis of global DNA methylation, these methods are very costly and time consuming, rendering them impracticable for DNA methylation analysis of large sample sizes [20]. Previous studies have demonstrated that the placenta is characterized by global DNA hypomethylation, usually a hallmark of various cancers. Next to global DNA hypomethylation, the placenta shares many features found in metastatic tumors, including rapid proliferation, invasiveness, and angiogenesis [21]. It was hypothesized that global DNA hypomethylation might support the unique functions of this organ [21-23]. Accordingly, alterations in the degree of global DNA methylation might be associated with altered placental function and disease. Until now, there are no large scale clinical studies that characterized global placental DNA methylation, assessed by an absolute quantification of the genomic 5-methylcytosine $(5 \mathrm{mC})$ content, in healthy and GDM afflicted pregnancies [24]. Thus, the aim of this study was to analyze global DNA methylation in over a thousand placental samples by the current gold standard method, LC-MS/MS, to truly asses the degree of global placental DNA methylation in uncomplicated pregnancies and to investigate whether GDM is associated with alterations in global placental DNA methylation.

\section{Results}

Table 1 displays detailed descriptive statistics of the 1030 mothers and their newborns and descriptive statistics of the study population grouped according to the presence or absence of GDM. Considering that patient recruitment was performed at a university clinic, the cohort did not display any uncommon features. The mean age of the mothers was $30.0 \pm 5.9$ years, and the mean BMI before pregnancy was $23.1 \pm 4.5 \mathrm{~kg} / \mathrm{m}^{2}$; $93.5 \%$ of all mothers were of Caucasian, $0.9 \%$ of African, $3.7 \%$ of Asian, and $1.9 \%$ of other ethnic background. Of all mothers, 5.4 \% developed diabetes during pregnancy. The overall mean degree of placental DNA methylation was $3.01 \pm 0.48 \%$. Data were normally distributed. Also shown in Table 1 are detailed descriptive statistics of the study population grouped according to the presence of GDM $(n=56)$ or no GDM $(n=974)$. Mothers with GDM had a significantly higher degree of placental global DNA methylation (3.22 \pm 0.63 vs. $3.00 \pm 0.46 \% ; p=0.013 ; \pm \mathrm{SD}$, Fig. 1$)$, were older $(31.9$ \pm 5.1 vs. $29.8 \pm 5.9$ years; $p=0.011 ; \pm \mathrm{SD}$ ), and had higher HbA1c concentrations ( $58 \pm 3.3$ vs. $42 \pm 6.6 \mathrm{mmol} / \mathrm{mol}$; $p<0.0001 ; \pm \mathrm{SD})$ and a significantly elevated BMI at 
Table 1 Descriptive data of all mother/child pairs and grouped according to GDM

\begin{tabular}{|c|c|c|c|c|}
\hline \multirow[t]{2}{*}{ Maternal characteristics } & \multirow{2}{*}{$\begin{array}{l}\text { All mothers } \\
(n=1030)\end{array}$} & \multicolumn{3}{|l|}{ Presence of GDM } \\
\hline & & No GDM $(n=974)$ & $\mathrm{GDM}(n=56)$ & $p$ value $^{a}$ \\
\hline Maternal age, years & $30.0 \pm 5.9$ & $29.8 \pm 5.9$ & $31.9 \pm 5.1$ & 0.011 \\
\hline Ethnicity (Caucasian, non-Caucasian), \% & $93.5 / 6.5$ & $93.5 / 6.5$ & $92.9 / 7.1$ & 0.842 \\
\hline Maternal height, $\mathrm{cm}$ & $166.9 \pm 7.0$ & $167.0 \pm 6.9$ & $166.4 \pm 8.4$ & 0.637 \\
\hline Body mass index before pregnancy, $\mathrm{kg} / \mathrm{m}^{2}$ & $23.1 \pm 4.5$ & $23.0 \pm 4.4$ & $24.8 \pm 5.8$ & 0.027 \\
\hline Body mass index $3 r d$ trimester, $\mathrm{kg} / \mathrm{m}^{2}$ & $27.6 \pm 4.5$ & $27.5 \pm 4.4$ & $29.6 \pm 5.3$ & 0.005 \\
\hline Hypertension before/during pregnancy, \% & $2.3 / 3.8$ & $2.3 / 3.6$ & $1.8 / 7.1$ & $0.809 / 0.331$ \\
\hline Diabetes mellitus before/during pregnancy, \% & $0.0 / 5.4$ & $0.0 / 0.0$ & $0.0 / 100.0$ & - \\
\hline Diabetes in family, \% & 38.1 & 37.7 & 44.6 & 0.300 \\
\hline Mean systolic blood pressure 3rd trimester, $\mathrm{mmHg}$ & $116.2 \pm 11.1$ & $116.3 \pm 11.1$ & $114.1 \pm 10.9$ & 0.159 \\
\hline Mean diastolic blood pressure 3rd trimester, $\mathrm{mmHg}$ & $70.3 \pm 7.5$ & $70.4 \pm 7.5$ & $69.4 \pm 8.4$ & 0.345 \\
\hline Smoking before/during pregnancy, \% & $35.3 / 13.6$ & $35.5 / 13.7$ & $32.1 / 12.5$ & $0.613 / 0.801$ \\
\hline Placental DNA methylation, \% & $3.01 \pm 0.48$ & $3.00 \pm 0.46$ & $3.22 \pm 0.63$ & 0.013 \\
\hline Parity number $\leq 1 / \geq 2, \%$ & $75.7 / 24.3$ & $75.9 / 24.1$ & $72.2 / 27.8$ & 0.545 \\
\hline $\mathrm{s} / \mathrm{p} 2$ or more miscarriages, $\%$ & 6.5 & 6.4 & 8.9 & 0.449 \\
\hline Twin gestations, \% & 2.1 & 2.1 & 3.6 & 0.445 \\
\hline Gestational age at delivery, weeks & $38.7 \pm 2.1$ & $38.7 \pm 2.1$ & $38.4 \pm 1.8$ & 0.056 \\
\hline Preterm birth ( $<37$ weeks), \% & 10.3 & 10.4 & 8.9 & 0.728 \\
\hline Birth weight, $g$ & $3339.6 \pm 634.8$ & $3329.8 \pm 627.1$ & $3509.6 \pm 742.5$ & 0.039 \\
\hline AGA/SGA/LGA, \% & $77.7 / 13.0 / 9.4$ & 78.6/12.9/8.6 & $62.5 / 14.3 / 23.2$ & 0.001 \\
\hline Birth length, $\mathrm{cm}$ & $50.6 \pm 3.2$ & $50.6 \pm 3.1$ & $50.3 \pm 5.0$ & 0.626 \\
\hline Child head circumference, $\mathrm{cm}$ & $34.7 \pm 1.7$ & $34.7 \pm 1.7$ & $34.6 \pm 1.8$ & 0.719 \\
\hline Ponderal index, $\mathrm{kg} / \mathrm{m}^{3}$ & $25.5 \pm 2.5$ & $25.4 \pm 2.5$ & $26.5 \pm 3.0$ & 0.002 \\
\hline Mode of delivery (spontaneous, OVD, c-section; \%) & $67.1 / 7.4 / 25.5$ & $67.9 / 7.7 / 24.4$ & $56.4 / 3.6 / 40.0$ & 0.030 \\
\hline Child sex, male/female, \% & $51.7 / 48.3$ & $51.6 / 48.4$ & $53.6 / 46.4$ & 0.780 \\
\hline Apgar score at 5 min & $9.3 \pm 1.0$ & $9.3 \pm 1.0$ & $9.3 \pm 0.9$ & 0.996 \\
\hline Apgar score at $10 \mathrm{~min}$ & $9.6 \pm 0.8$ & $9.6 \pm 0.8$ & $9.5 \pm 0.7$ & 0.137 \\
\hline Maternal HbA1c, \% & $6.1 \pm 0.7$ & $58 \pm 3.3$ & $42 \pm 6.6$ & $<0.0001$ \\
\hline
\end{tabular}

Data are given as mean \pm SD or percentage

a Comparison between "GDM" and "no GDM"

the beginning and in the third trimester of pregnancy $\left(24.8 \pm 5.8\right.$ vs. $23.0 \pm 4.4 \mathrm{~kg} / \mathrm{m}^{2} ; p=0.027 ; 29.6 \pm 5.3$ vs. $\left.27.5 \pm 4.4 \mathrm{~kg} / \mathrm{m}^{2} ; p=0.005\right)$. Newborns of GDM mothers had a significantly increased birth weight $(3509.6 \pm 742.5$ vs. $3329.8 \pm 627.1 \mathrm{~g} ; p=0.039)$, had an increased ponderal index $(26.5 \pm 3.0$ vs. $25.4 \pm 2.5 ; p=0.002)$, and were more often delivered by c-section ( 40.0 vs $24.4 \%$; $p=0.030$ ). Furthermore, the distribution of appropriate (AGA), small (SGA), and large (LGA) for gestational age newborns was significantly shifted towards a higher prevalence of LGA births in GDM mothers $(62.5 \%$ AGA/14.3 \% SGA/23.2 \% LGA vs. 78.6 \% AGA/12.9 \% SGA/8.6 \% LGA; $p=0.001 ;)$. LGA was also associated with significantly increased placental DNA methylation $(3.19 \pm 0.55 \%)$ compared to SGA $(3.01 \pm 0.43 \% ; p<0.01)$ and AGA $(2.99 \pm 0.47 \% ; p<0.001)$.
Bivariate logistic regression showed a highly significant correlation between placental DNA methylation and presence of GDM in an unadjusted model $(\operatorname{Exp}(B): 2.373 ; 95 \%$ CI 1.425-3.954; $p=0.0009$ ). To further categorize this relationship, quintiles of placental DNA methylation were generated (five groups of $n=206$ ) and analyzed in crosstabs for the frequency distribution of gestational diabetes. Figure 2 shows a cross tabulation of placental DNA methylation ranked in quintiles and the occurrence of GDM. The frequency of GDM was evenly distributed in quintiles 1-4 with frequencies ranging between 2.9 and $5.3 \%$, only in the fifth quintile a significantly higher GDM frequency of $10.7 \%$ was found (Pearson chi square 16.127; $p=0.003$; Fig. 2). This observation was even more significant after restratification into two groups, the first consisting of placental DNA methylation quintiles $1-4(n=824)$ and the 


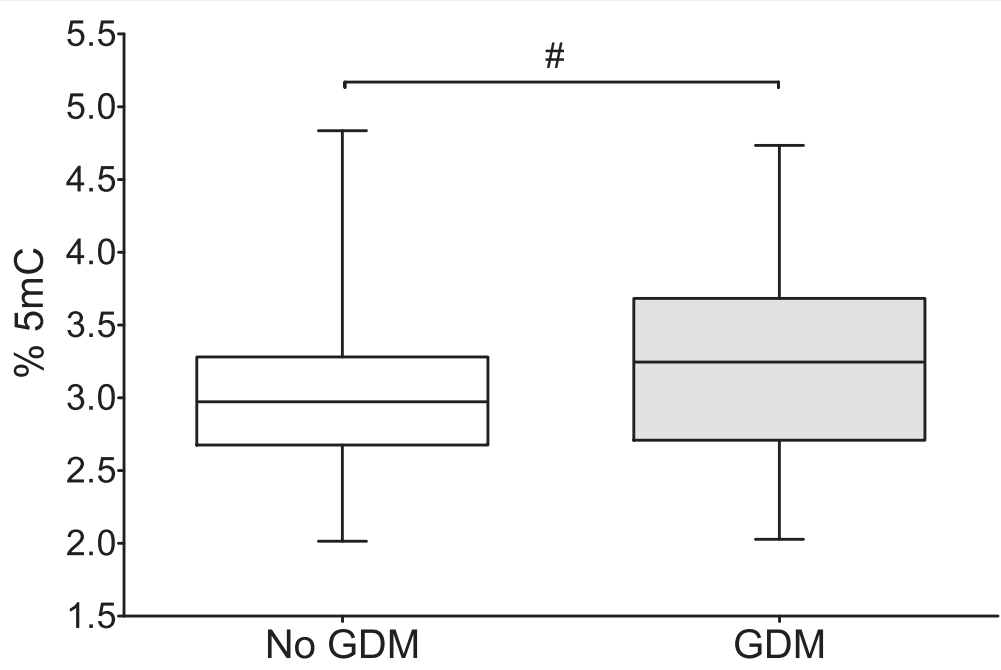

Fig. 1 Box and whiskers plot displaying the mean global placental DNA $5 \mathrm{mC}$ content, according to the presence or absence of GDM. Mothers with GDM had significantly higher mean levels (3.00\%; min $2.02 \%$; max $4.84 \%$ ) of $5 \mathrm{mC}$ than mothers without GDM (3.22 \%; $\min 2.03 \%$ max $4.73 \%$ ); \#: $p=0.013$

second of methylation quintile $5(n=206)$ (Pearson chisquare 13.766; $p=0.0002$; Table 2).

Table 2 shows detailed descriptive statistics of the study population according to the abovementioned stratification into lower degrees of placental DNA methylation (quintiles $1-4 ; n=824$ ) versus high placental DNA methylation (quintile $5 ; n=206$ ). There were significant differences regarding the ethnic composition of the highest methylation group vs. methylation quintiles $1-4$, with more nonCaucasians in the highest methylation group (9.7 vs. $5.7 \%$; $p=0.037$ ). There was a significantly higher frequency of
GDM in the highest methylation group (10.7 vs. $4.1 \%$; $p=$ 0.0002). Moreover, a significant increase of LGA births was observed in the highest methylation group (73.0\% AGA, 12.7 \% SGA, 14.2 \% LGA vs. 78.8 \% AGA, $13.0 \%$ SGA, $8.2 \%$ LGA; $p=0.028)$. Additionally, the Apgar score 10 min postnatally was significantly reduced in the highest methylation group $(9.5 \pm 0.8$ vs. $9.6 \pm 0.7 ; p=0.011)$.

\section{Adjusted bivariate logistic regression models}

To demonstrate that a high degree of placental DNA methylation is independently associated with GDM,

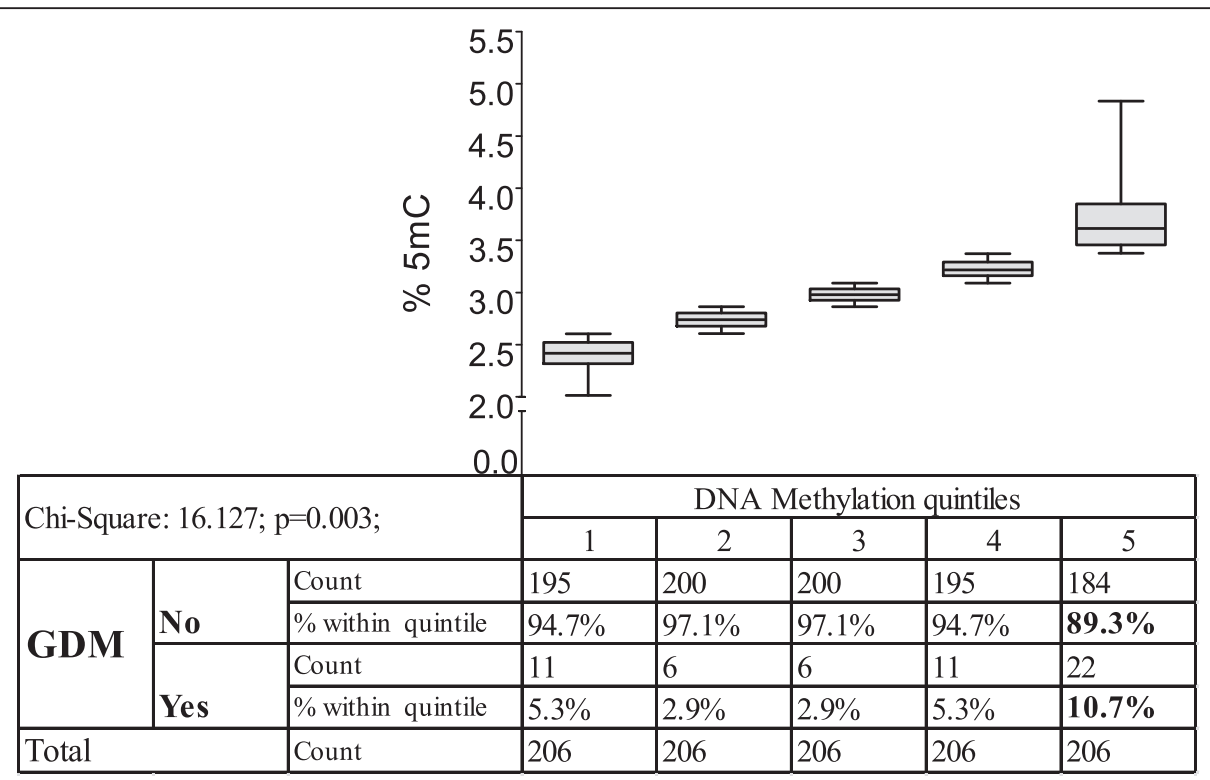

Fig. 2 Crosstabulation of GDM and placental DNA methylation ranked in quintiles. Ranges of placental DNA $5 \mathrm{mC}$ are depicted on top each respective quintile as box and whisker plots (mean; min; max) 
Table 2 Descriptive data of the mother/child pairs grouped according to the degree of placental DNA methylation

\begin{tabular}{|c|c|c|c|}
\hline \multirow[t]{3}{*}{ Maternal characteristics } & \multicolumn{3}{|c|}{ Degree of placental DNA methylation } \\
\hline & Quintiles 1-4 & Quintile 5 & $p$ value $^{a}$ \\
\hline & $(n=824)$ & $(n=206)$ & \\
\hline Maternal age, years & $29.9 \pm 6.0$ & $30.3 \pm 5.5$ & 0.407 \\
\hline Ethnicity (Caucasian, non-Caucasian), \% & $94.3 / 5.7$ & $90.3 / 9.7$ & 0.037 \\
\hline Maternal height, $\mathrm{cm}$ & $167.0 \pm 6.9$ & $166.5 \pm 7.3$ & 0.365 \\
\hline Body mass index before pregnancy, $\mathrm{kg} / \mathrm{m}^{2}$ & $23.2 \pm 4.5$ & $22.8 \pm 4.4$ & 0.094 \\
\hline Body mass index $3 r d$ trimester, $\mathrm{kg} / \mathrm{m}^{2}$ & $27.6 \pm 4.5$ & $27.4 \pm 4.3$ & 0.801 \\
\hline Hypertension before/during pregnancy, $\%$ & $2.0 / 3.5$ & $3.4 / 4.9$ & $0.200 / 0.443$ \\
\hline Diabetes mellitus during pregnancy, $\%$ & 4.1 & 10.7 & 0.0002 \\
\hline Diabetes in family, \% & 38.1 & 38.2 & 0.964 \\
\hline Mean systolic blood pressure 3rd trimester, mmHg & $116.4 \pm 11.0$ & $115.3 \pm 11.5$ & 0.202 \\
\hline Mean diastolic blood pressure 3rd trimester, $\mathrm{mmHg}$ & $70.4 \pm 7.5$ & $70.0 \pm 7.5$ & 0.491 \\
\hline Smoking before/during pregnancy, \% & $35.4 / 13.3$ & $34.6 / 14.7$ & $0.828 / 0.635$ \\
\hline Placental DNA methylation, \% & $2.84 \pm 0.32$ & $3.71 \pm 0.34$ & $<0.0001$ \\
\hline Parity number $<2 / \geq 2, \%$ & $76.1 / 23.9$ & $73.8 / 26.2$ & 0.481 \\
\hline $\mathrm{s} / \mathrm{p} 2$ or more miscarriages, $\%$ & 6.3 & 7.3 & 0.613 \\
\hline twin gestations, $\%$ & 1.8 & 3.4 & 0.161 \\
\hline Gestational age at delivery, weeks & $38.7 \pm 2.1$ & $38.8 \pm 1.8$ & 0.989 \\
\hline Preterm birth (<37 weeks), \% & 10.3 & 10.3 & 0.983 \\
\hline Birth weight, g & $3334.8 \pm 628.3$ & $3358.5 \pm 661.4$ & 0.634 \\
\hline AGA/SGA/LGA, \% & $78.8 / 13.0 / 8.2$ & $73.0 / 12.7 / 14.2$ & 0.028 \\
\hline Birth lenght, $\mathrm{cm}$ & $50.6 \pm 3.1$ & $50.5 \pm 3.6$ & 0.951 \\
\hline Child head circumference, $\mathrm{cm}$ & $34.7 \pm 1.7$ & $34.6 \pm 1.7$ & 0.436 \\
\hline Ponderal index, kg/m3 & $25.5 \pm 2.5$ & $25.5 \pm 2.7$ & 0.943 \\
\hline Mode of delivery (spontaneous, OVD, c-section; \%) & $66.2 / 8.1 / 25.8$ & $70.1 / 5.2 / 24.7$ & 0.387 \\
\hline Child sex, male/female, \% & $52.3 / 47.7$ & $49.8 / 50.2$ & 0.522 \\
\hline Apgar score at $5 \mathrm{~min}$ & $9.3 \pm 1.0$ & $9.2 \pm 1.1$ & 0.084 \\
\hline Apgar score at $10 \mathrm{~min}$ & $9.6 \pm 0.7$ & $9.5 \pm 0.8$ & 0.011 \\
\hline Maternal HbA1c, m & $43 \pm 7.7$ & $45 \pm 8.7$ & 0.257 \\
\hline
\end{tabular}

Data are given as mean \pm SD or percentage

${ }^{a}$ Comparison between "Quintiles 1-4" and "Quintile 5"

adjusted bivariate logistic regression models were calculated. To account for confounding, the models were adjusted for available parameters known to be risk factors for GDM [6]. Risk factors included in the models were maternal age, BMI at the beginning of pregnancy, a history of recurrent ( $\geq 2)$ miscarriages (yes; no), ethnic background (Caucasian; non-Caucasian), and family history of type 2 diabetes (yes; no). Model A used these confounders together with placental DNA methylation as a continuous variable. In this model, placental DNA methylation was significantly associated with the presence of GDM $((\exp ) \mathrm{B}=$ 2.408; 95 \% CI 1.427-4.063; $p=0.001$; Table 3). In model B, placental DNA methylation stratified into the before mentioned two groups of high placental DNA methylation (quintile $5 ; n=206$ ) and lower degrees of placental DNA methylation (quintiles $1-4 ; n=824$ ) was used. Grouped placental DNA methylation was associated with the presence of GDM even more significantly $((\exp ) \mathrm{B}=2.999 ; 95 \%$ CI 1.691-5.316; $p=0.0002$; Table 3).

\section{Adjusted ANCOVA model}

To demonstrate that GDM is independently associated with global placental DNA methylation, an ANCOVA model was calculated and adjusted for predictors of DNA methylation evinced in previous methylation studies $[25,26]$. These factors included smoking status before pregnancy (yes/no), ethnic background (Caucasian; non-Caucasian), sex of the child (male/female), and age 
Table 3 Model A: logistic regression investigating an association between placental DNA methylation and GDM; model B: logistic regression investigating an association between placental DNA methylation grouped into the fifth quintile $(n=206)$ versus quintiles $1-4(n=824)$ and GDM

\begin{tabular}{|c|c|c|c|c|c|c|}
\hline \multirow{2}{*}{$\begin{array}{l}\text { Model A } \\
\text { Constant }-8.647 \pm 1.589 ; p<0.0001\end{array}$} & \multirow[t]{2}{*}{ B } & \multirow[t]{2}{*}{ S.E. } & \multirow[t]{2}{*}{ Sig. } & \multirow[t]{2}{*}{$\operatorname{Exp}(B)$} & \multicolumn{2}{|c|}{$95 \% \mathrm{Cl}$ for $\operatorname{Exp}(\mathrm{B})$} \\
\hline & & & & & Lower & Upper \\
\hline Maternal age, years & 0.061 & 0.026 & 0.017 & 1.063 & 1.011 & 1.118 \\
\hline BMI beginning of pregnancy, $\mathrm{kg} / \mathrm{m}^{2}$ & 0.067 & 0.025 & 0.008 & 1.069 & 1.018 & 1.124 \\
\hline S/p 2 or more miscarriages, $\%$ & -0.128 & 0.502 & 0.798 & 0.880 & 0.329 & 2.351 \\
\hline Ethnicity (Caucasian, other) & -0.111 & 0.558 & 0.842 & 0.895 & 0.300 & 2.669 \\
\hline Diabetes in family (yes/no) & -0.318 & 0.289 & 0.271 & 0.728 & 0.413 & 1.281 \\
\hline Placental DNA methylation, \% & 0.879 & 0.267 & 0.001 & 2.408 & 1.427 & 4.063 \\
\hline \multirow{2}{*}{$\begin{array}{l}\text { Model B } \\
\text { Constant }-5.240 \pm 1.275 ; p<0.0001\end{array}$} & \multirow[t]{2}{*}{ B } & \multirow[t]{2}{*}{ S.E. } & \multirow[t]{2}{*}{ Sig. } & \multirow[t]{2}{*}{$\operatorname{Exp}(B)$} & \multicolumn{2}{|c|}{$95 \% \mathrm{Cl}$ for $\operatorname{Exp}(\mathrm{B})$} \\
\hline & & & & & Lower & Upper \\
\hline Maternal age, years & 0.061 & 0.026 & 0.017 & 1.063 & 1.011 & 1.118 \\
\hline BMI beginning of pregnancy, $\mathrm{kg} / \mathrm{m}^{2}$ & 0.073 & 0.025 & 0.004 & 1.076 & 1.024 & 1.13 \\
\hline S/p 2 or more miscarriages, (\%) & -0.143 & 0.501 & 0.775 & 0.867 & 0.325 & 2.314 \\
\hline Ethnicity (Caucasian, other) & -0.139 & 0.554 & 0.802 & 0.87 & 0.294 & 2.579 \\
\hline Diabetes in family (yes/no) & -0.314 & 0.289 & 0.277 & 0.731 & 0.415 & 1.286 \\
\hline Placental DNA methylation (grouped) & 1.098 & 0.292 & 0.0002 & 2.999 & 1.691 & 5.316 \\
\hline
\end{tabular}

of the mother. GDM was the strongest predictor of global placental DNA methylation $(\mathrm{B}=0.215 ; 95 \% \mathrm{CI}$ $0.087-0.342 ; p=0.001$; Table 4) in this model. Additionally, the maternal smoking status before pregnancy was also significantly associated with global placental DNA methylation $(\mathrm{B}=-0.064 ; 95 \% \mathrm{CI}-0.126-0.002$; $p=0.044$; Table 4). Ethnicity of the mother, sex of the child, and maternal age showed no association with global placental DNA methylation (Table 4).

\section{Discussion}

The current study showed in a normally constituted cohort of delivering woman that there is a significant positive correlation between the degree of placental DNA methylation and GDM, i.e., higher levels of placental $5 \mathrm{mC}$ are associated with a higher frequency of GDM. Analyzing the mean levels of placental $5 \mathrm{mC}$ according to the presence or absence of GDM showed significantly higher mean values in GDM mothers. For a better understanding of the relationship between methylation and the risk for GDM, mothers were ranked in quintiles according to the degree of placental DNA methylation. This revealed a significantly elevated frequency of GDM in the fifth quintile. Calculating different bivariate logistic regression models with placental DNA methylation as continuous and categorical variable, adjusted for known risk factors of GDM, underlined an independent association between placental DNA hypermethylation and GDM. An ANCOVA model adjusted for known factors influencing DNA methylation further substantiated the independent association between global placental DNA hypermethylation and GDM.

One limitation of the current study is that no large data sets of continuous variables describing GDM were available, only categorical variables displaying the final diagnosis. Yet, measured term HbA1c concentrations in

Table 4 ANCOVA analysis of the interaction between factors known to influence global DNA methylation, GDM, and global placental DNA methylation

\begin{tabular}{|c|c|c|c|c|c|c|}
\hline \multirow{2}{*}{$\begin{array}{l}\text { Dependent variable: DNA } \\
\text { methylation; } r^{2}=0.016\end{array}$} & \multirow[t]{2}{*}{ B } & \multirow[t]{2}{*}{ S.E. } & \multirow[t]{2}{*}{ Power } & \multirow[t]{2}{*}{ Sig. } & \multicolumn{2}{|c|}{$95 \% \mathrm{Cl}$ for $\mathrm{B}$} \\
\hline & & & & & Lower & Upper \\
\hline Intercept & 3.06 & 0.091 & 1.000 & $<0.0001$ & 2.881 & 3.239 \\
\hline GDM (yes/no) & 0.215 & 0.065 & 0.911 & 0.001 & 0.087 & 0.342 \\
\hline Smoking before pregnancy (yes/no) & -0.064 & 0.032 & 0.521 & 0.044 & -0.126 & -0.002 \\
\hline Ethnicity (Caucasian, other) & 0.112 & 0.061 & 0.457 & 0.064 & -0.007 & 0.231 \\
\hline Sex of the child (male/female) & -0.032 & 0.03 & 0.191 & 0.279 & -0.09 & 0.026 \\
\hline Maternal age, years & 0.000 & 0.003 & 0.05 & 0.955 & -0.005 & 0.005 \\
\hline
\end{tabular}


a subset of mothers $(n=94)$, which were significantly elevated in GDM mothers, reinforced a correct diagnosis of GDM. Another limitation of this study is the usage of placental tissue without focusing on a specific placental cell type. Given the large sample size ( $>1000$ placenta samples), purification of specific placental cell types was not feasible. However, it was shown by MethylC-seq analysis that global methylation in whole rhesus placental tissue was almost identical compared to isolated rhesus trophoblast cell methylation with a correlation of 0.89 [21]. Next to the mentioned limitations, this study exhibits several strengths. To the best of our knowledge, it is by now the largest study of its kind analyzing placental DNA methylation and clinical readouts in 1030 mothers. Moreover, it is the first study that uses a robust quantitative assessment of placental global DNA methylation, employing the current gold standard LC-MS/MS [24]. All other studies investigating placental DNA methylation so far were either small, employed only semiquantitative methods of measuring global DNA methylation, or were focused on specific DNA methylation [9-12, 27]. Given the absence of studies with a comparable study design in regard to sample size, analyzed tissue, and the method of global DNA methylation assessment, interpretation of the results of the current study in context with available literature warrants caution.

Average levels of global placental DNA methylation were $3.00 \pm 0.46 \%$ in uncomplicated pregnancies. This is in agreement with another study analyzing global placental DNA methylation using HPLC, also demonstrating global DNA hypomethylation in comparison to average global DNA methylation levels observed in somatic tissues [28].

The current study demonstrated a positive association between GDM and global placental DNA methylation. Notwithstanding, a previous preliminary study by Nomura et al. showed a negative association between global placental DNA methylation and GDM [9]. However, as only 50 placenta samples were analyzed for global DNA methylation, the observed difference in results is most likely attributable to the $\sim 20$-fold smaller study size. Additionally, the seminquantitative luminometric methylation assay was used for the measurement of global DNA methylation, which was shown to be outperformed by other approaches of global DNA methylation assessment, especially regarding inter-assay comparability $[9,24,29]$.

Two studies, investigating placental DNA methylation in GDM using the Illumina Infinium 450K BeadChips array, found a predominance of hypermethylation at methylation variable positions in GDM exposed placental samples [11, 12]. However, such arrays only cover about $\sim 1.5 \%$ of all genomic CpGs [14]. Therefore, the results of these studies have limited value in discussing the current observations [14].
Several clinical studies, investigating global DNA methylation in type 2 diabetes showed higher levels of global DNA methylation in different types of peripheral blood cells of diabetic patients [30-36]. Global methylation in these studies was assessed by LC/MS-MS [30, 33-35] or LC/MS-MS validated methods [31] or by measuring surrogate parameters of global DNA methylation like LINE-1 or Alu elements [32, 36]. The analysis of global DNA methylation in leukocytes is a well used method in epidemiologic studies to display associations between global DNA methylation and disease [35, 37, 38]. However, whether changes in global leukocyte DNA methylation associated with an insult (e.g., diabetes) also reflect aligned methylation changes in other tissues remains elusive. Nevertheless, a general hypothesis raised by Zhao et al., speculating that a putative link between global DNA hypermethylation and diabetes could be genomic instability, might also apply for findings of the current study [32]. The hypothesis is supported by findings of other studies [39-41], and there is ample amount of evidence that genomic instability is not only a hallmark of cancer but also associated with insulin resistance [42-44]. An underlying factor bearing implications for both genomic instability and DNA hypermethylation might be oxidative stress. Literature suggests that oxidative stress is involved in the development of metabolic diseases [45]. Diabetes itself is associated with increased oxidative stress, and it is well described that oxidative stress can induce DNA damage, another important factor in the development of diabetes [43, 45-47]. It was also shown that reactive oxygen species regulate the activity of DNA methyltransferases and catalyze the methylation of DNA [48, 49]. Moreover, it was demonstrated in animal models that an upregulation of the activity or the expression of DNA methyltransferases is observed in different types of diabetes [48, 50, 51]. Data from these recent animal experiments support a positive association between a diabetic metabolic state and global DNA methylation and additionally delineated putative mechanisms, connecting diabetes, oxidative stress, and global DNA hypermethylation [50,51]. Zhong et al. have shown in a streptozotocin animal model of gestational diabetes that maternal diabetes induces an increased expression of DNA methyltransferases, increased DNA methyltransferase activity, and increased global DNA methylation (measured by MethylFlash Methylated DNA Quantification Kit which analyzes global $5 \mathrm{mC}$ content) in E8.75 embryos. Notably, treatment with the polyphenol epigallocatechin gallate, which was shown to exert anti-oxidative effects and to inhibit DNA methyltransferase activity, abrogated these changes [51-53].

\section{Conclusions}

In summary, this study provides the first large scale evidence that placental global DNA hypermethylation is 
associated with GDM independent of established risk factors. The results of the study are in agreement with other studies; however, many of the comparable studies investigated DNA methylation in type 2 diabetes, in other organs than the placenta or by different methods of global DNA methylation assessment. Nevertheless, there is substantial evidence in literature from both clinical and preclinical experimental studies supporting an association between a diabetic metabolic state and global DNA hypermethylation. The results of the current study have to be confirmed using comparable methods, to substantiate our understanding of global DNA methylation involvement in disease. In general, a harmonization of applied methodology for the measurement of global DNA methylation is warranted. Differently designed studies will be needed to demonstrate a causal relationship between global DNA hypermethylation and GDM and to elucidate the still very elusive question whether aberrant global DNA methylation is involved in the pathogenesis of GDM or a consequence of this disease.

\section{Methods}

\section{Ethics, consent, and permissions}

The study was approved by the ethics committee of the university hospital Charité, Berlin, Germany. All clinical investigations were conducted according to the principles expressed in the Declaration of Helsinki. Written, informed consent was obtained from all partaking mothers prior to data collection.

\section{Clinical study}

This observational all-comers study included 1063 mothers delivering at the obstetrics department of Campus Charité Mitte, Berlin, Germany. Structured interviews were performed with the partaking mothers. Eleven mothers with overt diabetes before pregnancy, nine cases of preeclampsia, and 13 cases with incomplete data of the most important variables and confounders were excluded from the statistical analyses. Given a potential overlap regarding pathophysiological processes leading to preeclampsia and GDM and the low sample number of preeclamptic placentas in the current study, it stood to reason to exclude mother with preeclampsia $[9,54]$. In total, 1030 mothers were included into the statistical analyses. The majority of mothers $(n=963 ; 93.5 \%)$ were of Caucasian ethnicity, while 67 mothers $(6.5 \%)$ had other ethnic backgrounds. Data from the "Mutterpass" documenting the results of follow ups during pregnancy were also collected. The following data were available for the dataset: age, ethnicity, body height, body mass index (BMI) at the beginning of pregnancy, body mass index (BMI) at the third trimester of pregnancy, parity, diabetes mellitus before or during pregnancy, family history of diabetes, incidence of hypertension before and during pregnancy, smoking before and during pregnancy, systolic and diastolic blood pressure measurements recorded during pregnancy, and in a small subset $(n=94)$ of mothers, maternal HbA1c levels at term. GDM was screened and assessed in all mothers according to the practice guideline of the German Diabetes Association (DGG) and the German Association for Gynaecology and Obstetrics (DGGG) [55]. Biometric data of the newborn were collected during the routine postnatal examination. Gestational age at delivery was based on the last menstrual period, anamnestically assessed during the first pregnancy examination. The following data of the newborn were added to the database: birth weight, birth length, head circumference, child sex, Apgar score 5 min postnatally and Apgar score 10 min postnatally. A standardized placenta sample-1 complete cotyledon (cross section of all layers) from similar locations-was collected and immediately frozen and stored at $-20^{\circ} \mathrm{C}$. For the extraction of DNA a sample of chorionic villi was obtained from the whole cotyledon.

Data were analyzed using SPSS version 20.0 (SPSS, Inc, Chicago, IL, USA). Depending on normal distribution, unpaired $t$ test or Mann-Whitney $U$ test was used when comparing mean values of two groups. For the comparison of categorical variable distribution, chi-square test was used. Bivariate logistic regression was used to analyze the relationship of continuous and categorical data with a categorical outcome, to confirm relevant confounding variables that had an independent influence, and to adjust for these in different statistical models. To calculate associations between a continuous dependent variable and both categorical and continuous independent variables, ANCOVA models were used. Bar graphs were calculated and compiled with Graphpad Prism 5 (GraphPad Software Inc., La Jolla, California, USA). Probability values $<0.05$ were considered significant. The authors had full access to the data and take full responsibility for its integrity.

\section{Analysis of DNA methylation}

DNA was extracted using a QIAamp DNA Mini Kit from Qiagen (Hilden, Germany) together with a RNase A digestion according to the manufacturer's protocol. The concentration and quality of the RNA-free DNA solution were determined by a NanoDrop ND-1000 spectrophotometer. DNA hydrolysis was carried out using DNA Degradase Plus from Zymo Research (Freiburg, Germany). Briefly, $1 \mu \mathrm{g}$ of genomic DNA was mixed with $2.5 \mu \mathrm{L} 10 \times$ DNA Degradase Reaction Buffer, and $1 \mu \mathrm{L}$ DNA Degradase Plus and filled up with water to a volume of $25 \mu \mathrm{L}$. DNA hydrolysis was stopped after $4 \mathrm{~h}$ at $37{ }^{\circ} \mathrm{C}$ by adding $75 \mu \mathrm{L}$ of $0.1 \%$ formic acid. Agarose gel electrophoresis using $200 \mathrm{ng}$ of the digested DNA was employed in order to control the completeness of digestion. Seventy microliters of the hydrolised DNA 
samples were further diluted with $280 \mu \mathrm{L} 0.1 \%$ formic acid to yield a final concentration of $2 \mathrm{ng}$ digested $\mathrm{DNA} / \mu \mathrm{L}$. DNA methylation was assessed by liquid chromatography-electrospray ionization/multi-stage mass spectrometry (LC-ESI/MS/MS) technique as described previously [56]. LC-ESI/MS/MS was performed with an Agilent 1200 series HPLC system connected to an Agilent 6530 Accurate-Mass Q-TOF instrument with Jet StreamInterface (Waldbronn, Germany). For chromatographic separation a Waters (Milford, MA) X-BridgeTM C18 $4.6 \mathrm{~mm} \times 150 \mathrm{~mm}(3.5-\mu \mathrm{m}$ particle size $)$ protected by a Waters X-BridgeTM C18 $4.6 \mathrm{~mm} \times 20 \mathrm{~mm}$ guard column (5- $\mu \mathrm{m}$ particle size) was used. $0.1 \%$ formic acid in water (solvent A) and $0.1 \%$ formic acid in methanol (solvent B) were chosen as mobile phases. The linear gradient elution was $4-20 \%$ of solvent $B$ in $10 \mathrm{~min}$ at a constant flow rate of $0.5 \mathrm{~mL} / \mathrm{min}$. Fifty microliters of the diluted DNA hydrolysis samples, typically containing 100-ng digested DNA, were injected. The optimized ESI-MS/MS parameters in the positive ion mode were as follows: gas temperature, $250{ }^{\circ} \mathrm{C}$; drying gas flow, $8 \mathrm{~L} / \mathrm{min}$; nebulizer pressure, 60 psig; sheat gas temperature, $300{ }^{\circ} \mathrm{C}$; capillary voltage $4000 \mathrm{~V}$; and collision energy $7 \mathrm{~V}$ for $\mathrm{dC}, 13 \mathrm{~V}$ for $5 \mathrm{mdC}$, and $10 \mathrm{~V}$ for dG. Quantification was accomplished in selected reaction monitoring (SRM) mode by monitoring a transition pair of $\mathrm{m} / \mathrm{z} 228.0979 / 112 . .0505$ for $\mathrm{dC}, \mathrm{m} / \mathrm{z}$ $242 . .1135 / 126.0662$ for $5 \mathrm{mdC}$, and $\mathrm{m} / \mathrm{z} 268.1040 / 152.0780$ for $\mathrm{dG}$, which was used as an internal standard for the measurement. The scan time was $333 \mathrm{~ms}$ for each pair. The deoxyribonucleosides 2 '-deoxyguanosine (dG) monohydrate, 5-methyl-2' -deoxycytidine (5mdC) and 2'-deoxycytidine $(\mathrm{dC})$ were purchased from ABCR (Karlsruhe, Germany). Hering sperm DNA was obtained from SigmaAldrich (Hamburg, Germany). Nuclease-free water used for DNA extraction was purchased from Roth (Karlsruhe, Germany). LC-MS-grade water, methanol, and formic acid were purchased from VWR international, Inc. (Dresden, Germany). The global level of DNA methylation was calculated as the percentage of DNA methylation as follows: DNA methylation \% $=5$ - methyl- $2^{\prime}$-deoxycytidine $(5 \mathrm{mdC}) /\left[5\right.$-methyl-2' -deoxycytidine $(5 \mathrm{mdC})+2^{\prime}$ deoxycytidine $(\mathrm{dC})] \times 100 \%$.

\section{Abbreviations}

5mC, 5-methylcytosine; AGA, appropriate for gestational age; DGG German Diabetes Association; DGGG German Association for Gynaecology and Obstetrics; GDM, gestational diabetes mellitus; IADPSG, International Association of Diabetes in Pregnancy Study Group; LC-MS/MS, Liquid chromatography tandem mass spectrometry; LGA, large for gestational age; OVD, operative vaginal delivery; SGA, small for gestational age

\section{Acknowledgements}

Not applicable.

Funding

This study was partially funded by the Deutsche Forschungsgemeinschaft (DFG grant No. Ho1665/5-2 to Prof. Hocher).

\section{Availability of data and materials}

The dataset contains indirect identifiers. As there is some risk of identification, the dataset was not approved for publication in a freely accessible manner by the local ethics committee.

\section{Authors' contributions}

$\mathrm{BH}$ was responsible for the clinical study design. TP, TS, and BH conducted the clinical study, edited the manuscript, and contributed to the discussion. SEDP and CN performed the measurements of global DNA methylation and edited the manuscript. SEDP contributed to the discussion. CR wrote the manuscript and analyzed the data. BK coordinated the measurement of global DNA, edited the manuscript, and contributed to the discussion. BH is the guarantor of this work and had full access to all the data in the study and takes responsibility for the integrity of the data and the accuracy of the data analysis. All authors read and approved the final manuscript.

\section{Competing interests}

The authors declare that they have no competing interests.

\section{Consent for publication}

Not applicable.

\section{Ethics approval and consent to participate}

The study was approved by the institutional ethics committee of the university hospital Charité, Berlin, Germany. All clinical investigations were conducted according to the principles expressed in the Declaration of Helsinki. Written, informed consent was obtained from all partaking mothers prior to data collection.

\section{Author details}

'Department of Experimental Nutritional Medicine, Institute of Nutritional Science, University of Potsdam, Arthur-Scheunert-Allee 114-116, Nuthetal, Potsdam 14558, Germany. ${ }^{2}$ Department of Toxicology, Institute of Nutritional Science, University of Potsdam, Nuthetal, Germany. ${ }^{3}$ Department of Nephrology, Campus Charité Mitte, University Hospital Charité, Berlin, Germany. ${ }^{4}$ Center for Cardiovascular Research (CCR), Campus Charité Mitte, University Hospital Charité, Berlin, Germany. ${ }^{5}$ Faculty of Biotechnology, University of Surabaya, Surabaya, Indonesia. ${ }^{6}$ Diaverum Deutschland, Potsdam, Germany. ${ }^{7}$ Institut für Laboratoriumsmedizin, Berlin, Germany. ${ }^{8}$ Department of Basic Medicine, Medical College of Hunan Normal University, Changsha, China.

Received: 26 April 2016 Accepted: 11 July 2016

Published online: 26 July 2016

\section{References}

1. Lappas M, Hiden U, Desoye G, Froehlich J, Hauguel-de Mouzon S, Jawerbaum A. The role of oxidative stress in the pathophysiology of gestational diabetes mellitus. Antioxid Redox Signal. 2011;15:3061-100.

2. Schneider S, Bock C, Wetzel M, Maul H, Loerbroks A. The prevalence of gestational diabetes in advanced economies. J Perinat Med. 2012;40:511-20.

3. Coustan DR. Gestational diabetes mellitus. Clin Chem. 2013;59:1310-21.

4. Hartling L, Dryden DM, Guthrie A, Muise M, Vandermeer B, Aktary WM, et al. Screening and diagnosing gestational diabetes mellitus. Evidence Report/ Technology Assessment no. 210. AHRQ Publication no. 12(13)-E021-EF. Rockville, MD: Agency for Healthcare Research and Quality; 2012.

5. Gauster M, Desoye G, Tötsch M, Hiden U. The placenta and gestational diabetes mellitus. Curr Diab Rep. 2012;12:16-23.

6. Reece EA, Leguizamón G, Wiznitzer A. Gestational diabetes: the need for a common ground. Lancet. 2009;373:1789-97.

7. Schaefer-Graf P-DD med UM, Kautzky-Willer U-PD med A. Diabetes mellitus und Schwangerschaft. In: Schneider PD med H, Husslein U-PD med P-W, Schneider U-PD med KTM, editors. Die Geburtshilfe. Berlin: Springer; 2011. p. 435-56.

8. Gabbay-Benziv R, Baschat AA. Gestational diabetes as one of the "great obstetrical syndromes" - the maternal, placental, and fetal dialog. Best Pract Res Clin Obstet Gynaecol. 2015;29:150-5.

9. Nomura Y, Lambertini L, Rialdi A, Lee M, Mystal EY, Grabie M, et al. Global methylation in the placenta and umbilical cord blood from pregnancies with maternal gestational diabetes, preeclampsia, and obesity. Reprod Sci. 2014;21:131-7. 
10. Bouchard L, Hivert M-F, Guay S-P, St-Pierre J, Perron P, Brisson D. Placental adiponectin gene DNA methylation levels are associated with mothers' blood glucose concentration. Diabetes. 2012;61:1272-80.

11. Ruchat S-M, Houde A-A, Voisin G, St-Pierre J, Perron P, Baillargeon J-P, et al. Gestational diabetes mellitus epigenetically affects genes predominantly involved in metabolic diseases. Epigenetics. 2013;8:935-43.

12. Finer S, Mathews C, Lowe R, Smart M, Hillman S, Foo L, et al. Maternal gestational diabetes is associated with genome-wide DNA methylation variation in placenta and cord blood of exposed offspring. Hum Mol Genet. 2015;24(11):3021-9.

13. Binder AM, LaRocca J, Lesseur C, Marsit CJ, Michels KB. Epigenome-wide and transcriptome-wide analyses reveal gestational diabetes is associated with alterations in the human leukocyte antigen complex. Clin Epigenetics. 2015;7:79.

14. Busche S, Shao X, Caron M, Kwan T, Allum F, Cheung WA, et al. Population whole-genome bisulfite sequencing across two tissues highlights the environment as the principal source of human methylome variation. Genome Biol. 2015;16:290.

15. Patrushev LI, Kovalenko TF. Functions of noncoding sequences in mammalian genomes. Biochemistry (Mosc). 2014;79:1442-69.

16. Gregory TR. Synergy between sequence and size in large-scale genomics. Nat Rev Genet. 2005;6:699-708.

17. Gelfman S, Cohen N, Yearim A, Ast G. DNA-methylation effect on cotranscriptional splicing is dependent on GC architecture of the exonintron structure. Genome Res. 2013;23:789-99.

18. Lev Maor G, Yearim A, Ast G. The alternative role of DNA methylation in splicing regulation. Trends Genet. 2015;31:274-80.

19. Reddington JP, Pennings $S$, Meehan RR. Non-canonical functions of the DNA methylome in gene regulation. Biochem J. 2013;451:13-23.

20. Kurdyukov S, Bullock M. DNA methylation analysis: choosing the right method. Biology (Basel) [Internet]. 2016 [cited 2016 Jun 11];5. Available from: http://www.ncbi.nlm.nih.gov/pmc/articles/PMC4810160/

21. Schroeder DI, Jayashankar K, Douglas KC, Thirkill TL, York D, Dickinson PJ, et al. Early developmental and evolutionary origins of gene body DNA methylation patterns in mammalian placentas. PLoS Genet. 2015;11, e1005442.

22. Chatterjee A, Macaulay EC, Rodger EJ, Stockwell PA, Parry MF, Roberts HE, Slatter TL, Hung NA, Devenish CJ, Morison IM. Placental Hypomethylation Is More Pronounced in Genomic Loci Devoid of Retroelements. G3 (Bethesda). 2016;6(7):1911-21. doi:10.1534/g3.116.030379.

23. Bianco-Miotto T, Mayne BT, Buckberry S, Breen J, Lopez CMR, Roberts CT. Recent progress towards understanding the role of DNA methylation in human placental development. Reproduction. 2016;152:R23-30.

24. Liu J, Hesson LB, Ward RL. Liquid Chromatography Tandem Mass Spectrometry for the Measurement of Global DNA Methylation and Hydroxymethylation. Journal of Proteomics \& Bioinformatics [Internet] Available from: http://www.omicsonline.org/proteomics-bioinformaticsabstract.php?abstract_id=15772

25. Tajuddin SM, Amaral AFS, Fernandez AF, Rodriguez-Rodero S, Rodriguez RM, Moore LE, et al. Genetic and non-genetic predictors of LINE-1 methylation in leukocyte DNA. Environ Health Perspect. 2013:121:650-6.

26. Boeke CE, Baccarelli A, Kleinman KP, Burris HH, Litonjua AA, Rifas-Shiman SL, et al. Gestational intake of methyl donors and global LINE-1 DNA methylation in maternal and cord blood: prospective results from a folatereplete population. Epigenetics. 2012;7:253-60.

27. Lesseur C, Armstrong DA, Paquette AG, Li Z, Padbury JF, Marsit CJ. Maternal obesity and gestational diabetes are associated with placental leptin DNA methylation. Am J Obstet Gynecol. 2014;211(6):654.e1-9.

28. Fuke C, Shimabukuro M, Petronis A, Sugimoto J, Oda T, Miura K, et al. Age related changes in 5-methylcytosine content in human peripheral leukocytes and placentas: an HPLC-based study. Ann Hum Genet. 2004;68:196-204.

29. Lisanti S, Omar WAW, Tomaszewski B, De Prins S, Jacobs G, Koppen G, et al. Comparison of methods for quantification of global DNA methylation in human cells and tissues. PLoS One. 2013;8.

30. Maghbooli Z, Larijani B, Emamgholipour S, Amini M, Keshtkar A, Pasalar P. Aberrant DNA methylation patterns in diabetic nephropathy. J Diabetes Metab Disord. 2014;13:69.

31. Simar D, Versteyhe S, Donkin I, Liu J, Hesson L, Nylander V, et al. DNA methylation is altered in B and NK lymphocytes in obese and type 2 diabetic human. Metab Clin Exp. 2014;63:1188-97.

32. Zhao J, Goldberg J, Bremner JD, Vaccarino V. Global DNA methylation is associated with insulin resistance: a monozygotic twin study. Diabetes. 2012;61:542-6.
33. Maghbooli Z, Hossein-Nezhad A, Larijani B, Amini M, Keshtkar A. Global DNA methylation as a possible biomarker for diabetic retinopathy. Diabetes Metab Res Rev. 2014;31(2):183-9.

34. Maghbooli Z, Hossein-Nezhad A, Larijani B, Pasalar P, Keshtkar AA. Association between alterations in global DNA methylation and predisposing factors in diabetes: a high pressure liquid chromatography based study. Minerva Med. 2015;106:221-31.

35. Maghbooli Z, Hossein-nezhad A, Larijani B, Amini M, Keshtkar A. Global DNA methylation as a possible biomarker for diabetic retinopathy. Diabetes Metab Res Rev. 2015;31:183-9.

36. Pearce MS, McConnell JC, Potter C, Barrett LM, Parker L, Mathers JC, et al. Global LINE-1 DNA methylation is associated with blood glycaemic and lipid profiles. Int J Epidemiol. 2012;41:210-7.

37. Terry MB, Delgado-Cruzata L, Vin-Raviv N, Wu HC, Santella RM. DNA methylation in white blood cells: association with risk factors in epidemiologic studies. Epigenetics. 2011;6:828-37.

38. Kim YO, Li C, Sun BK, Kim JS, Lim SW, Choi BS, et al. Preconditioning with 1,25-dihydroxyvitamin D3 protects against subsequent ischemia-reperfusion injury in the rat kidney. Nephron Exp Nephrol. 2005;100:e85-94.

39. Walters RJ, Williamson EJ, English DR, Young JP, Rosty C, Clendenning M, et al. Association between hypermethylation of DNA repetitive elements in white blood cell DNA and early-onset colorectal cancer. Epigenetics. 2013:8:748-55.

40. Neale RE, Clark PJ, Fawcett J, Fritschi L, Nagler BN, Risch HA, et al. Association between hypermethylation of DNA repetitive elements in white blood cell DNA and pancreatic cancer. Cancer Epidemiol. 2014;38:576-82.

41. Liao LM, Brennan P, van Bemmel DM, Zaridze D, Matveev $V$, Janout $V$, et al. LINE-1 methylation levels in leukocyte DNA and risk of renal cell cancer. PLoS One. 2011;6.

42. Moran LJ, Noakes M, Clifton PM, Norman RJ, Fenech MF. Genome instability is increased in lymphocytes of women with polycystic ovary syndrome and is correlated with insulin resistance. Mutat Res. 2008;639:55-63.

43. Attia SM, Helal GK, Alhaider AA. Assessment of genomic instability in normal and diabetic rats treated with metformin. Chem Biol Interact. 2009:180:296-304.

44. Binici DN, Karaman A, Coşkun M, Oğlu AU, Uçar F. Genomic damage in patients with type-2 diabetes mellitus. Genet Couns. 2013:24:149-56.

45. Rani V, Deep G, Singh RK, Palle K, Yadav UCS. Oxidative stress and metabolic disorders: pathogenesis and therapeutic strategies. Life Sci. 2016;148:183-93.

46. Milic M, Frustaci A, Del Bufalo A, Sánchez-Alarcón J, Valencia-Quintana R, Russo $P$, et al. DNA damage in non-communicable diseases: a clinical and epidemiological perspective. Mutat Res. 2015;776:118-27.

47. Dong D, Yu J, Wu Y, Fu N, Villela NA, Yang P. Maternal diabetes triggers DNA damage and DNA damage response in neurulation stage embryos through oxidative stress. Biochem Biophys Res Commun. 2015;467:407-12.

48. Wei D, Loeken MR. Increased DNA methyltransferase 3b (Dnmt3b)-mediated CpG island methylation stimulated by oxidative stress inhibits expression of a gene required for neural tube and neural crest development in diabetic pregnancy. Diabetes. 2014;63:3512-22.

49. Hai Z, Zuo W. Aberrant DNA methylation in the pathogenesis of atherosclerosis. Clin Chim Acta. 2016;456:69-74.

50. Williams KT, Schalinske KL. Tissue-specific alterations of methyl group metabolism with DNA hypermethylation in the Zucker (type 2) diabetic fatty rat. Diabetes Metab Res Rev. 2012;28:123-31.

51. Zhong J, Xu C, Reece EA, Yang P. The green tea polyphenol EGCG alleviates maternal diabetes-induced neural tube defects by inhibiting DNA hypermethylation. Am J Obstet Gynecol. 2016. doi:10.1016/j.ajog.2016.03.009.

52. Fang MZ, Wang Y, Ai N, Hou Z, Sun Y, Lu H, et al. Tea polyphenol (-)-epigallocatechin-3-gallate inhibits DNA methyltransferase and reactivates methylation-silenced genes in cancer cell lines. Cancer Res. 2003;63:7563-70.

53. Legeay S, Rodier M, Fillon L, Faure S, Clere N. Epigallocatechin gallate: a review of its beneficial properties to prevent metabolic syndrome. Nutrients. 2015;7:5443-68

54. Liu L, Zhang X, Rong C, Rui C, Ji H, Qian Y, et al. Distinct DNA methylomes of human placentas between pre-eclampsia and gestational diabetes mellitus. Cell Physiol Biochem. 2014;34:1877-89.

55. Kleinwechter H, Schäfer-Graf U, Bührer C, Hoesli I, Kainer F, Kautzky-Willer A, et al. Gestational diabetes mellitus (GDM) diagnosis, therapy and follow-up care. Exp Clin Endocrinol Diabetes. 2014;122:395-405.

56. Dwi Putra SE, Neuber C, Reichetzeder C, Hocher B, Kleuser B. Analysis of genomic DNA methylation levels in human placenta using liquid chromatography-electrospray ionization tandem mass spectrometry. Cell Physiol Biochem. 2014;33:945-52. 